\title{
Being of "two minds": Assessing vacillating and simultaneous ambivalence with the density matrix
}

\author{
James Camparo $^{1,2}$ • Lorinda B. Camparo ${ }^{3}$
}

Published online: 19 July 2017

(C) Psychonomic Society, Inc. 2017

\begin{abstract}
Ambivalence is a common experience that permeates a broad range of research. Unfortunately, quantifying ambivalence has proven a daunting task, with researchers limited to studying vacillating ambivalence, VA (i.e., temporal oscillations between favor/disfavor evaluations of an attitude object). Here, we demonstrate the use of the density matrix to measure both VA and what we term "simultaneous ambivalence" (SA): ambivalence that manifests itself as "in the moment" concurrent favor/disfavor evaluations. In a methodological study we gave participants the option of either single-responding or doubleresponding to questionnaire items regarding a controversial topic (i.e., affirmative action). Since standard statistical procedures provide no means for analyzing double responses, such data are routinely treated as "bad." As demonstrated here, the density matrix provides an unambiguous and relatively easy means of accounting for double responses, which is our indicator of SA. Our data are well explained by a mixture model, with participants divided into two nearly equal groups of SA and non-SA participants, and provide evidence that the general phenomenon of SA transcends differences of gender and ethnicity.
\end{abstract}

James Camparo

james.c.camparo@aero.org

1 Physical Sciences Laboratories, The Aerospace Corporation, 2310 E. El Segundo Blvd., El Segundo, CA 90245, USA

2 Department of Physics and Astronomy, Whittier College, 13406 Philadelphia St., Whittier, CA 90608, USA

3 Department of Psychological Sciences, Whittier College, 13406 Philadelphia St., Whittier, CA 90608, USA
Further, the density matrix data are consistent with viewing SA and VA as distinct ambivalence constructs.

Keywords Attitudes $\cdot$ Ambivalence $\cdot$ Density matrix . Quantum probability $\cdot$ Likert scale $\cdot$ Affirmative action

There can be little argument that attitudes are central to the behavioral sciences (Crano et al. 2010), and that understanding their structure, resiliency, and evolution cuts across disciplines ranging from the social sciences to consumer marketing to political science. Quite generally, an attitude is defined as "a psychological tendency that is expressed by evaluating a particular entity with some degree of favor or disfavor" (Eagly \& Chaiken, 1993), which often suggests a view of attitudes as stable points falling somewhere along a favorable/unfavorable line. Researchers, however, have now come to recognize that such a static one-dimensional understanding of attitudes may be too limited (Jonas \& Ziegler, 2007; Thompson, Zanna, \& Griffin, 1995). In particular, the cognitive processes involved in attitude-object evaluation can be subtle and complex (Touragneau \& Rasinski, 1988; Zaller \& Feldman, 1992), with individuals able to maintain at a single moment both favorable and unfavorable attitude-object evaluations. In a word, individuals can be ambivalent: they may endorse the pros and cons of affirmative action, or they may agree and disagree with a presidential candidate's stance in America's pro-choice/pro-life debates. Not only does ambivalence bear on the specific attitudes appearing in psychology, political science, and marketing (Basinger \& Lavine, 2005; Conner, Sparks, Povey, James, Shepherd, \& Armitage, 2002; Kachadourian, Fincham, \& Davila, 2005; McGraw, Hasecke, \& Conger, 2003; Russell et al. 2011; Zemborain \& Johar, 2007), but the nature of ambivalence raises important theoretical questions regarding its structure (Baek, 2010; Song 
\& Ewoldsen, 2015) and antecedents (Thompson \& Zanna, 1995), along with questions of attitude stability (Armitage \& Conner, 2000).

Notwithstanding its ubiquity, the single most significant problem facing researchers when dealing with ambivalence is one of methodology: how are opposing, yet simultaneous, favorable/unfavorable evaluations to be merged into a single quantifiable parameter? Since psychology's earliest days, variants of the semantic differential and Likert-scale techniques have been employed for attitude assessments (Himmelfarb, 1993; Spector, 1992). These techniques, however, were designed under a linear bipolar paradigm, and therefore cannot be employed for ambivalence research without modification. Kaplan (1972) was one of the first to modify these techniques, and all present-day objective ambivalence measures trace back to that work (Locke \& Braun, 2009; Priester \& Petty, 1996; Thompson \& Zanna, 1995). Briefly, and in broad outline, valence assessments are made of an attitude object, providing a respondent's "favorable score" and their "unfavorable score." These two scores are then combined using one of several mathematical formulae, yielding a numerical assessment of the subject's ambivalence. For ease of reference, we will call these various approaches to quantifying ambivalence $\mathrm{V}$-measures ( $\mathrm{V}$ for valence).

There are, unfortunately, limitations with V-measures. Most importantly, since V-measures probe ambivalence through valence, what one actually quantifies are oscillations in attitude, or what may be termed vacillating ambivalence (VA) (i.e., temporal fluctuations between favor/disfavor evaluations). Vacillating ambivalence, however, should be distinguished from simultaneous ambivalence (SA): ambivalence that manifests itself as "in-the-moment" concurrent favor/ disfavor evaluations. Nevertheless, previous research has failed to make the VA/SA distinction, primarily because Vmeasures only allow quantification of the one type.

Though vacillating and simultaneous ambivalence are likely related, their equivalence is another matter: holding simultaneous favor/disfavor evaluations of an attitude object (i.e., "being of two minds") would seem conceptually distinct from alternating between favor/disfavor evaluations (i.e., "flipflopping"). To be clear, we recognize that the VA/SA distinction may be subtle and complex, and will likely require a fair amount of research and thought before it is fully resolved. Our only contentions here are that (1) VA should be viewed as a separate construct from SA until proven otherwise, and that (2) the VA/SA distinction has been underappreciated to date primarily as a result of methodological limitations.

Another issue with V-measures is that they show poor correlation with participants' subjective ambivalence (NewbyClark, McGregor, \& Zanna, 2002; Priester \& Petty, 1996), sometimes termed felt ambivalence (Jonas \& Ziegler, 2007). While this poor correlation might be a simple consequence of present V-measure forms (e.g., the mathematical formulae that translate valence assessments into a VA number), it could just as likely reflect a fundamental difference between VA and felt ambivalence. For example, factors unrelated to an individual's recognition of their own ambivalence might affect oscillations in favor/disfavor evaluations (e.g., vertical inconsistency, which is an inconsistency between an explicit or controlled attitude and an implicit or automatic attitude, Baek, 2010). Simultaneous ambivalence, however, is expected to be a clear measure of felt ambivalence, since (for example) individuals will not double respond agree/disagree to a single questionnaire item unless they have some sense of their own ambivalence. Given the limitations of V-measures, and the conceptual distinction between VA and SA, it seems exigent to find means of quantifying SA both from a basic social sciences perspective, and more pragmatically from a need to draw true meaning from survey data.

Interestingly, an equivalent situation arose within the physics community in the 1950 s regarding nuclear magnetic resonance (NMR). Briefly, the protons in water molecules can exist in only two magnetic states: one in which their North poles point in the same direction as the North pole of an applied magnetic field (i.e., the "aligned" magnetic state), and one in which their North poles point in the opposite direction (i.e., the "anti-aligned" magnetic state). In NMR a radiofrequency signal forces the protons to exist simultaneously in both the aligned and anti-aligned magnetic states (Bushong, 1988), and in this way the protons become "simultaneously ambivalent" with regard to their direction in space. To describe NMR signals physicists employ a statistical tool called the density matrix, and over the years it has become standard methodology for describing systems of nuclei, atoms, and molecules in aligned/anti-aligned states (Blum, 1981; Fano, 1957). Following a trend to bring the mathematical tools of quantum physics to bear on difficult problems in psychology (Busemeyer, Wang, Khrennikov, \& Basieva, 2014; Busemeyer \& Wang, 2015), in this paper we consider the density matrix's ability to measure both VA and SA for an evaluative object that might be expected to elicit ambivalence. We wish to stress, however, that there is nothing inherently quantum mechanical in our use of the density matrix to describe ambivalence. Rather, it is a case where the mathematics of linear vector spaces is applicable to the quantum physics of atoms and nuclei as well as the analysis of questionnaire data.

\section{Necessity of double responses}

Individuals' attitudes are often assessed using ordinal responses to questionnaire items: participants are given a questionnaire dealing with (for example) affirmative action, and are asked to indicate their level of agreement or disagreement with the items. Of course, for a controversial topic an individual with an ambivalent attitude will almost certainly encounter 
items that elicit a two-category agree/disagree response. Unfortunately, by instructing the participant to "mark only one response per item," the researcher has created a methodological problem.

If the subject follows the researcher's direction, they might choose one component of theirambivalentstateas theresponse for thatparticularitem(e.g., "agree" foranagree/disagreeambivalent state). However, the subject is then not accurately conveying their true attitudinal state to the researcher. Often in such cases, if the subjectencountersasimilaritemlaterinthequestionnaire, theywill attemptto "balance" theiragreeresponsewithadisagreeresponse. This, of course, has the effectof converting theirSAattitudinalstate into a VA response. Alternatively, the ambivalent subject might choose the midpoint response for the item, since they neither fully agree nor disagree with the questionnaire item. This again is problematic,sincethesubjectisnowconvertingtheirSAattitudinalstate intoaresponsethatactuallyindicatesindifference.

If the ambivalent subject marks more than one response, attempting to better communicate their true state of ambivalence to the researcher, the double response is identified as "bad data." The researcher might then attempt to modify the response by randomly choosing between the two. For example, with an agree/disagree double response the researcher might re-code the response as agree after flipping a coin. However, the researcher has then (strictly speaking) manipulated the data set, and quite likely converted SA responses into VA responses if the coin-flipping occurs more than once. Alternatively, the researcher could simply ignore the response. This is also data manipulation, since the researcher is now eliminating ambivalent attitudes from the data set.

It would seem that the only escape from this methodological trap is for the researcher to allow double responses to questionnaire items. However, that solution gives the researcher a new and different methodological problem: how are they to code and analyze the participant's doubleresponses in a meaningful way? Our suggested solution to that problem lies with the density matrix.

\section{Overview of the density matrix}

The density matrix is a statistical tool whose origin traces to atomic and nuclear physics (Blum, 1981; Fano, 1957), where it is routinely employed to quantify an atom's ability to exist in opposing magnetic states - the basic phenomenon behind NMR (Bushong, 1988). Recently, however, the density matrix was appropriated for use in the social sciences (Camparo, 2013), and could be useful for ambivalence research since it provides a means of unambiguously quantifying double responses to questionnaire items. In brief the density matrix, $\rho$, corresponds to a square $\mathrm{N} \times \mathrm{N}$ array, where $\mathrm{N}$ is the number of categorical responses. The categorical responses are treated mathematically as independent basis vectors, $\left|\mathrm{C}_{\mathrm{i}}\right\rangle$, in a complex N-dimensional linear vector space. (Here, we employ Dirac's "bra ket" notation for vectors (Dirac, 1947; Louisell, 1973).) The density matrix is an operator in this space, and is constructed from an outer product of the basis vectors:

$\rho=\sum_{\mathrm{i}, \mathrm{j}}^{\mathrm{N}} \rho_{\mathrm{ij}}\left|C_{i}\right\rangle\left\langle C_{j}\right|$

Here, $\left\langle\mathrm{C}_{\mathrm{i}}\right|$ is the dual to $\left|\mathrm{C}_{\mathrm{i}}\right\rangle$. Thus, if $\left|\mathrm{C}_{\mathrm{i}}\right\rangle$ is represented as a column unit vector, then $\left\langle\mathrm{C}_{\mathrm{i}}\right|$ is represented as a row unit vector, and we have for the inner product of basis vectors $\left\langle C_{i}\right|$ $\left.C_{j}\right\rangle=\delta_{\mathrm{ij}}$.

We represent an individual's response to the $\mathrm{q}^{\text {th }}$ item on a questionnaire with a response vector, $\left|\Phi_{\mathrm{q}}\right\rangle$, which can be written as a linear superposition of the attitudinal basis state vectors (Camparo, 2013):

$$
\left|\Phi_{q}\right\rangle=\sum_{\mathrm{i}}^{\mathrm{N}} a_{\mathrm{i}}(q)\left|C_{i}\right\rangle \text { and }\left\langle\Phi_{q}\right|=\sum_{\mathrm{i}}^{\mathrm{N}} a_{i}^{*}(q)\left\langle C_{i}\right|
$$

where $a_{i} *$ is the complex conjugate of $a_{i}$, and the $a_{i}$ correspond to projections of the response vector onto the various axes of the space (i.e., the various possible response categories). So, for example, given a 5 -point Likert scale with $1=$ Strongly Disagree and $5=$ Strongly Agree, an ambivalent agree/disagree, double response to the $\mathrm{q}^{\text {th }}$ item on a questionnaire would be described by a normalized response vector:

$\left|\Phi_{q}\right\rangle=\frac{1}{\sqrt{2}}\left(\left|C_{2}\right\rangle+\left|C_{4}\right\rangle\right)$

Since the norm of all attitude vectors in the space is unity (i.e., $\left\langle\Phi_{q} \mid \Phi_{q}\right\rangle=1$ ), the square of the projection of any response vector onto a coordinate axis can be interpreted as giving the probability of the subject exhibiting that attitude for the item (Camparo, 2013): $\mathrm{P}_{\text {agree }}=\left|\left\langle\mathrm{C}_{4} \mid \Phi_{\mathrm{q}}\right\rangle\right|^{2}$.

The density matrix is essentially a means of categorizing and counting these response vectors for statistical analysis. First, we construct the density matrix for the $\mathrm{k}^{\text {th }}$ individual, $\boldsymbol{\rho}(\mathrm{k})$, by averaging the outer products of that individual's response vectors over all $\mathrm{M}$ questionnaire items:

$$
\begin{aligned}
\boldsymbol{\rho}(\mathrm{k}) & =\frac{1}{M} \sum_{\mathrm{q}=1}^{\mathrm{M}}\left|\Phi_{q}\right\rangle\left\langle\Phi_{q}\right| \\
& =\sum_{i, j}^{N}\left\{\frac{1}{M} \sum_{\mathrm{q}=1}^{\mathrm{M}} a_{i}^{*}(q) a_{j}(q)\right\}\left|C_{i}\right\rangle\left\langle C_{j}\right| \\
& =\sum_{i, j}^{N} \rho_{i j}(k)\left|C_{i}\right\rangle\left\langle C_{j}\right|
\end{aligned}
$$


The total density matrix of the sample is then simply an average over all subjects, $\mathrm{N}_{\mathrm{S}}$ :

$\rho_{\mathrm{ij}}=\frac{1}{\mathrm{~N}_{\mathrm{S}}} \sum_{k=1}^{N_{S}} \rho_{\mathrm{ij}}(\mathrm{k})$

Filling the density matrix is relatively straightforward. For a single response to a questionnaire item, one full count is obviously added to the corresponding diagonal density-matrix element. For a double response to a questionnaire item, a halfcount is added to each of the corresponding diagonal array elements, and a half-count to each of the corresponding offdiagonal array elements. Thus, for a 5-point Likert scale with $1=$ Strongly Disagree. . . 5 = Strongly Agree, an agree/disagree double response would yield $\rho_{\mathrm{ij}} \rightarrow \rho_{\mathrm{ij}}+1 / 2$ with $\mathrm{i}, \mathrm{j}=2,4$.

With regard to interpretation, the individual diagonal array elements represent the probability for obtaining any one of the categorical responses. In contrast, the off-diagonal elements give the probability for participants exhibiting simultaneous ambivalence. For example, for a 5-point Likert scale $\rho_{22}$ might equal the probability of disagree with $\rho_{44}$ equal to the probability of agree. The probability of a subject simultaneously agreeing and disagreeing to a questionnaire item would then equal the sum of the corresponding off-diagonal elements: $P_{\text {agree/disagree }}=\rho_{24}+\rho_{42}$.

Notice that the density matrix distinguishes between $\mathrm{P}_{\text {agree/ }}$

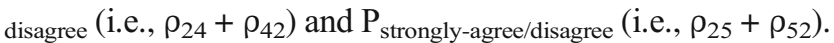
Thus, not only does the density matrix provide a ratio measure of the strength of ambivalence (e.g., $\mathrm{P}_{\text {agree/disagree) }}$ it distinguishes between different levels and symmetries of ambivalence (e.g., $\mathrm{P}_{\text {agree/disagree Vs. }} \mathrm{P}_{\text {strongly-agree/disagree }}$ Vs. $\mathrm{P}_{\text {agree/strong- }}$ ly-disagree). Clearly, the probability for participants showing any level of SA is the sum of all the off-diagonal elements (i.e., $P_{S A}=\sum_{\mathrm{i}, \mathrm{j}}^{\mathrm{N}} \rho_{\mathrm{ij}}\left(1-\delta_{i j}\right) \rightarrow$ the global strength or intensity of simultaneous ambivalence), and the probability of participants being in a non-SA attitudinal state is just $\mathrm{P}_{\text {non-SA }}=1-\mathrm{P}_{\mathrm{SA}}$. Note also that the probability of a respondent displaying SA $\left(\mathrm{P}_{\mathrm{SA}}\right)$ is clearly distinguished from the probability that a subject is indifferent to the attitude object $\left(P_{\text {indifferent }}=\rho_{33}\right)$.

The present study was designed to demonstrate and test the utility of the density matrix for analyzing data regarding an evaluative object that was expected to elicit VA and SA in participants. We had three goals for this study: (1) to determine whether or not a significant fraction of participants would exhibit SA through double-responding to questionnaire items if given the opportunity; (2) to examine the density matrix's ability to quantify and extract statistical information on SA; and (3) to employ the density matrix to take a preliminary first look at the general character of SA and its equivalence (or nonequivalence) to VA. Thus, our goal was not to explore participants' attitudes about affirmative action per se, nor was it to develop materials to maximize ambivalent thinking. Rather, affirmative action (as an evaluative object) and the questionnaire items were chosen as vehicles for instilling some level of ambivalence in the participants, which could then be assessed with the density matrix. Ambivalence towards any other attitude object would have suited the present work's purposes just as well.

\section{Method}

\section{Participants}

Undergraduates $(\mathrm{N}=325)$ from a small 4-year liberal arts college located in Southern California with a diverse student body participated in the study. Participants were primarily female (67\%), and included 34\% EuropeanAmericans (EA), 40\% Hispanics (HI) (overwhelmingly US born), 9\% Asian/Pacific Islanders, 12\% composite ethnicity, and $6 \%$ non-responders or other ethnic groups. The sample size for this methodological study was determined by two self-imposed constraints. First, we felt that a minimum of 30 SA participants was necessary for statistical purposes, and second we felt that we could not justify the density matrix's use for ambivalence research if the number of SA participants was less than $10 \%$ (especially since we were purposefully attempting to induce ambivalence). Consequently, we required a minimum of 300 participants. To obtain this population, data were collected in five waves over 2 years. One advantage to collecting the data in this fashion is that it allowed us to examine the consistency of the results over several independent trials. Although such a data collection method does not correspond to true replication, it does help guard against incidents of serendipitous population sampling (e.g., primarily drawing participants from a college class where affirmative action was recently debated).

\section{Procedures and materials}

Participants were instructed to read a one-page essay highlighting pro/con arguments related to affirmative action (see Appendix 1), and were then asked to rate their level of agreement/disagreement to eight statements on a 5-point Likert scale: the midpoint was identified by the statement "I truly have no opinion." The questionnaire considered affirmative action globally, with two of the items on the questionnaire worded as very general affirmative action statements, two items addressing gender affirmative action, and four items addressing ethnic affirmative action. (See Appendix 2 for the questionnaire items and the instructions to the participants.) Half the items on the questionnaire were biased pro affirmative action with the other half biased con affirmative action, and the questionnaire was limited to eight items in order to avoid potential fatigue 
effects. The purpose of the essay was to arouse any latent ambivalent attitudes participants might have held towards affirmative action via (for example) horizontal inconsistency (i.e., conflicting attitudes toward different attributes of an object; Baek, 2010), and the questionnaire items were worded so as to incite ambivalent thinking towards the attitude object. Roughly half the participants read the pro argument first with the others reading the con argument first. Participants were explicitly told that this questionnaire was different from others they may have taken, and that on this questionnaire they could mark one or two responses per item.

To distinguish truly ambivalent attitudes from cases where participants might have simply wanted a finer scale distinction, double responses were only counted as simultaneously ambivalent if they differed by at least one response category (e.g., agree/disagree). When double markings violated this rule (e.g., agree/strongly-agree), a coin was flipped to yield a single response. A participant was identified as simultaneously ambivalent if he/she responded to at least one questionnaire item with a valid double response.

\section{Results and discussion}

\section{General characteristics of subjects identified as simultaneously ambivalent}

As shown in Fig. 1a, for each of the data collection waves roughly half the participants indicated SA attitudes towards affirmative action by double responding to at least one questionnaire item; for the complete sample the fraction of (double-responding) SA participants was $49 \%$, which is shown by the dashed line. Thus, when survey respondents encounter questionnaire items towards which they may experience SA, a large fraction appear willing to take advantage of double responding if given the option.

Figure $1 \mathrm{~b}$ shows the fractions of SA males and females for each of the waves, and as will be discussed subsequently we found no evidence for a gender difference regarding SA for the present questionnaire and its focus on affirmative action. Though further research regarding gender differences and SA will likely prove to be profitable (e.g., focusing more tightly on specific aspects of affirmative action and its manifestations), Fig. $1 \mathrm{~b}$ illustrates that in general significant fractions of males and females can be expected to experience SA as defined by the double responding criterion.

Finally, Fig. 2 shows the breakdown of double responses with regard to the questionnaire items' focus on affirmative action. As might be expected, the items eliciting the largest fraction of double responses were those that asked subjects to consider affirmative action in its widest possible context (i.e., general affirmative action). Nevertheless, equivalently sized fractions of participants double responded to specific items that focused on gender and ethnicity issues.

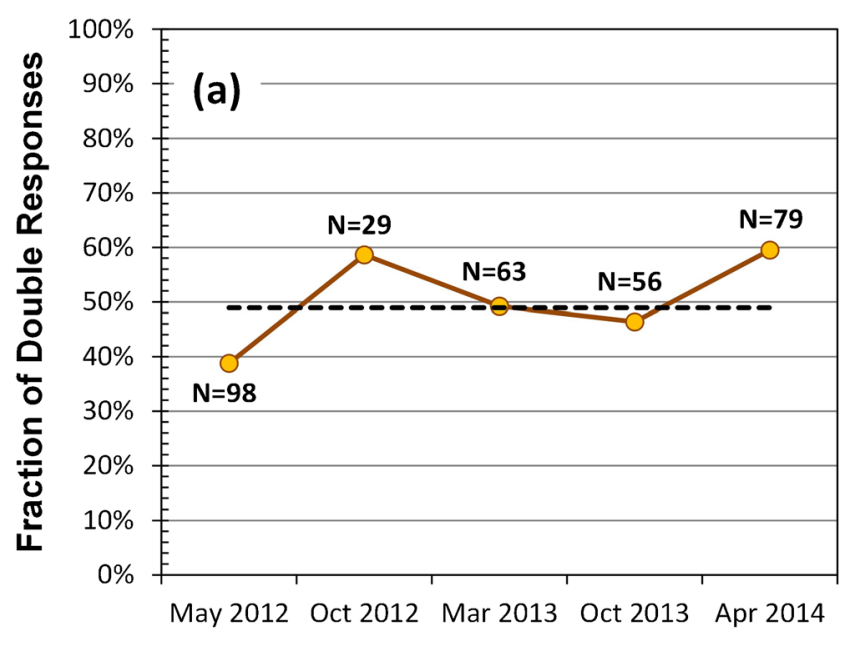

Date of Data Collection Wave

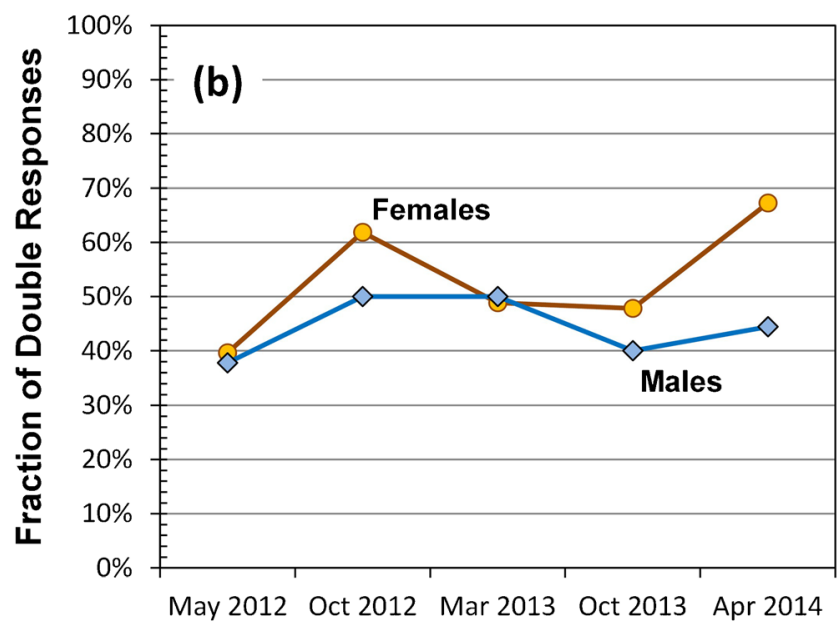

Date of Data Collection Wave

Fig. 1 Fraction of double responses. (a) For each of the data collection waves, this graph shows the fraction of participants who were identified as simultaneously ambivalent via double responding; the numbers indicate the total number of participants for that data wave, and the dashed line corresponds to the average. (b) For each of the data collection waves, this graph shows the fraction of male and female participants identified as simultaneously ambivalent via double responding: circles $\rightarrow$ female and diamonds $\rightarrow$ male

\section{Qualitative global features of the density matrix results}

Figure $3 \mathrm{a}$ and $\mathrm{b}$ show three-dimensional plots of the density matrix for (a) the non-SA participants, and (b) the SA participants. Clearly, for both non-SA and SA participants the density matrix shows polarization in the participants' valence: the density matrix elements along the diagonal are roughly equal in magnitude on the "disagree" and "agree" sides (though there is a slightly greater probability for disagree), with a very low density matrix value at "indifference." Though both nonSA and SA participants exhibited polarization, which could be analyzed using state multipoles (Camparo \& Camparo, 2013), polarization in this sample's density matrix by itself is not 


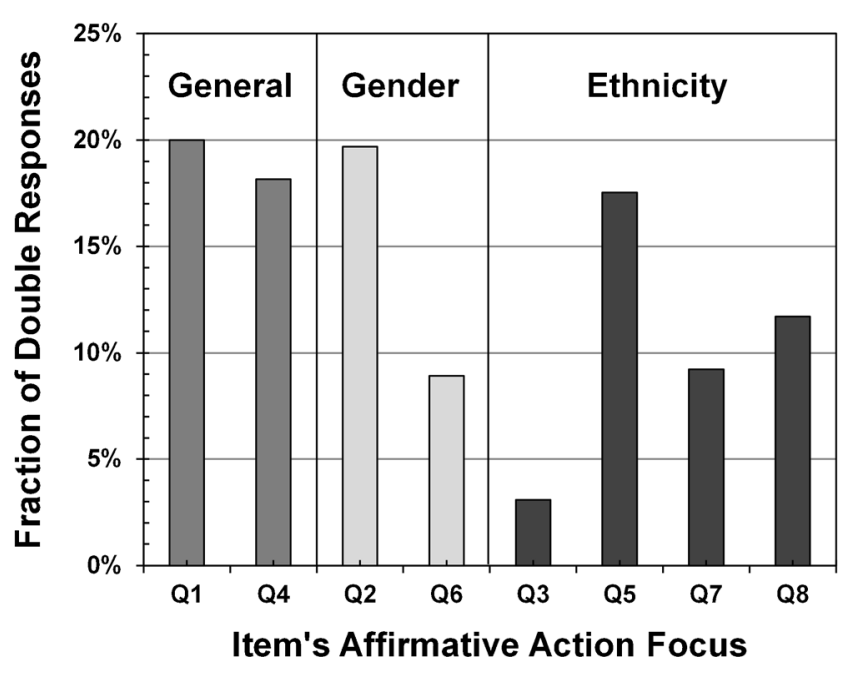

Fig. 2 Fraction of double responses. For each of the questionnaire items, grouped in terms of their affirmative action focus, this figure shows the fraction of double responses

necessarily evidence of ambivalence (neither SA nor VA). For example, polarization could be a consequence of subsets of respondents having different attitudes.

However, the presence of off-diagonal elements in the sample's density matrix is an unambiguous indicator of SA. Even though the non-SA and SA participants exhibited polarization in their valence attitude scores, the non-SA participants exhibited this polarization without ever responding agree/disagree simultaneously. Further, Fig. 3b clearly shows that the largest off-diagonal element for the SA participants corresponded to agree/disagree, which suggests that primarily only one level of SA was manifesting itself in this study.

Using each participant's density matrix, $\rho(\mathrm{k})$, an overall affirmative-action endorsement score, $\mathrm{S}(\mathrm{k})_{\text {endorse }}$, can be computed for each subject:

$S(k)_{\text {endorse }}=\sum_{J=1}^{5}(J-3) \rho_{J J}(k)$

Averaging over ethnicity and gender, we then computed endorsement scores for the non-SA and SA subjects, finding $M_{\text {non- }}$ $S_{S A}=-0.42(S E=0.05, S D=0.60)$ and $M_{S A}=-0.38(S E=0.04, S D$ $=0.51$ ). Thus, although Fig. $3 \mathrm{a}$ and $\mathrm{b}$ show clear qualitative differences in the response patterns of non-SA and SA participants (i.e., the presence or absence of off-diagonal elements), there is no meaningful difference in these two groups' mean endorsement of affirmative action (at least for this very general affirmative action questionnaire).

\section{A mixture model of ambivalence}

To analyze the probability distribution of $\mathrm{P}_{\mathrm{SA}}$ values for our sample, $p\left[\mathrm{P}_{\mathrm{SA}}\right]$, which is shown in Fig. 4, we assume that our respondents form a heterogeneous population of SA and non-
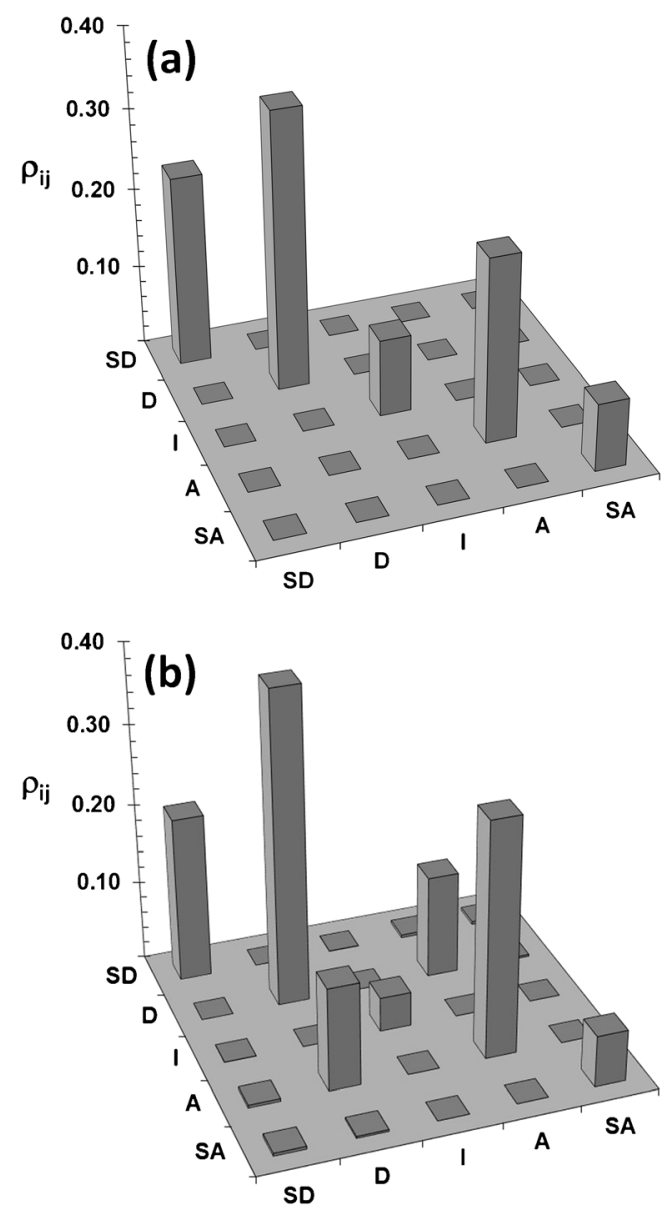

Fig. 3 Global view of the density matrix. (a) Average density matrix elements for the non-simultaneously ambivalent (SA) participants: SD = Strongly-Disagree, $\mathrm{D}=$ Disagree, $\mathrm{I}=$ Indifferent ("I truly have no opinion"), A = Agree, and SA = Strongly Agree. (b) Average density matrix elements for the SA participants

SA subjects (i.e., $\mathrm{p}\left[\mathrm{P}_{\mathrm{SA}}\right]$ conforms to a mixture model (Böhning \& Seidel, 2003)). Further, for the SA subjects we will make two additional assumptions:

1) The likelihood that an SA participant double responds to an item is independent of their response to any other item (i.e., the participants' responses to separate questionnaire items are statistically independent), and

2) SA participants make double responses randomly at an average rate equal to $\left\langle\mathrm{P}_{\mathrm{SA}}\right\rangle$, where $\langle\ldots\rangle$ indicates the average value of the term between the angled brackets.

Since these are the underlying assumptions for a Poisson probability distribution (Davenport, 1970; Mendenhall, Scheaffer, \& Wackerly, 1986), our model for $\mathrm{p}\left[\mathrm{P}_{\mathrm{SA}}\right]$ can be written as:

$p[r]=\left[(1-\theta)+\theta e^{-\lambda}\right][1-H(r)]+\theta \mathrm{H}(\mathrm{r}) e^{-\lambda} \frac{\lambda^{r}}{r !}$

where $\mathrm{r}$ is the number of double responses on an $\mathrm{N}$-item questionnaire: $\mathrm{r}=\mathrm{NP}_{\mathrm{SA}}$; and where $\mathrm{H}(\mathrm{r})$ is the Heaviside Unit 


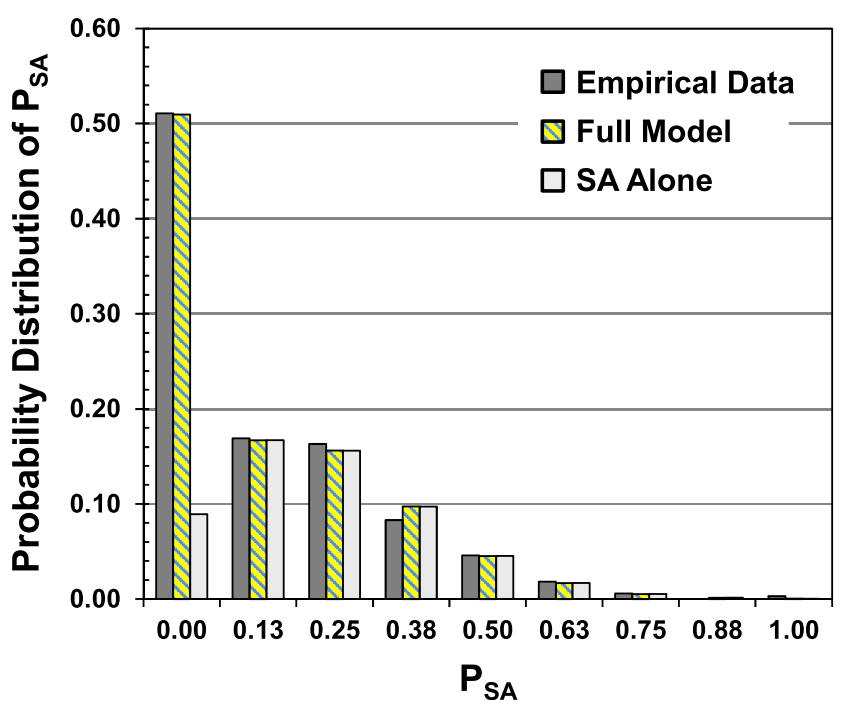

Fig. 4 Probability distribution of $\mathrm{P}_{\mathrm{SA}}$. The probability distribution of participants exhibiting a particular strength of simultaneous ambivalence, $\mathrm{P}_{\mathrm{SA}}: \mathrm{p}\left[\mathrm{P}_{\mathrm{SA}}\right]$. Equivalently, since $\mathrm{NP}_{\mathrm{SA}}$ corresponds to the number of double responses made on an $\mathrm{N}$-item questionnaire, this graph can also be understood as the probability distribution for participants making various numbers of double responses on our eight-item questionnaire. The dark gray bars correspond to the empirical data; the patterned bars correspond to the model probability distribution given by Eq. (7) using $\langle\theta\rangle$ and $\langle\lambda\rangle$ from the Markov Chain Monte Carlo (MCMC) analysis; the very light gray bars correspond to the model considering SA subjects alone

Step function: $\mathrm{H}(0)=0$ and $H(r \neq 0)=1$. In Eq. (7), $\theta$ is the fraction of SA participants in the heterogeneous sample, and $\lambda$ $=\langle\mathrm{r}\rangle=\mathrm{N}\left\langle\mathrm{P}_{\mathrm{SA}}\right\rangle$ (i.e., the average number of double responses on an N-item questionnaire).

The important point to note in Eq. (7) is that it contains only two free parameters: $\theta$ and $\lambda$, which can be evaluated via Bayes theorem:

$p[\theta, \lambda \mid D]=\frac{p[D \mid \theta, \lambda] \mathrm{p}(\theta) \mathrm{p}(\lambda)}{p(D)}$

where $\mathrm{p}[\mathrm{D} \mid \theta, \lambda]$ is the likelihood given by Eq. (7). We take $p(\theta)$ as a uniformly distributed prior between zero and one, and $p(\lambda)$ as a Gamma distributed prior for $\lambda$ (since this is the conjugate to the Poisson distribution): $\mathrm{p}(\lambda)=\lambda^{\alpha-1} \mathrm{e}^{-\lambda} / \Gamma(\alpha)$. Though $\alpha$ is a free parameter for the Gamma distribution (Marsaglia \& Tsang, 2000), our results were independent of its chosen value, at least for the range of $\alpha$ we considered: 0.5 $\leq \alpha \leq 2$. This range was chosen based on the data of Fig. $3 \mathrm{~b}$ (i.e., $\left\langle\mathrm{P}_{\mathrm{SA}}\right\rangle \sim 0.2$ ), in combination with the fact that $\alpha$ equals the prior mean value of $\lambda$. We solved for $p[\theta, \lambda \mid \mathrm{D}]$ using Markov Chain Monte Carlo (MCMC), and Fig. 5 is an exemplar scattergram of $\lambda$ vs. $\theta$ values that we obtained from the MCMC taking $\alpha=1$.

Employing the full data set (i.e., not distinguishing by gender or ethnicity), Fig. 6a and b shows the posterior probability density functions (PDFs) of $\theta$ and $\lambda$, respectively, while Fig. 4 compares the empirical probability distribution of $\mathrm{P}_{\mathrm{SA}}$ values (dark grey histogram bars) with the model distribution based on Eq. (7) using $\langle\theta\rangle$ and $\langle\lambda\rangle$ from the MCMC (patterned histogram bars). For the MCMC $10^{6}$ steps were taken, with an effective sample size (ESS) of 26,722 for $\theta$ and an ESS of 26,300 for $\lambda$. The agreement between the data and the model is very good, with a $\chi^{2}$ goodness-offit parameter equal to $0.058\left(\chi_{.05}^{2}=11.07\right.$ for five degrees of freedom) (Mendenhall, Scheaffer, \& Wackerly, 1986). For completeness, the very light gray bars in Fig. 4 show the model probability distribution for the SA subjects alone, clearly indicating that a fraction of subjects who did not double respond (i.e., subjects with $\mathrm{P}_{\mathrm{SA}}=0$ ) were nonetheless likely SA subjects.

Using the model probability distribution of Eq. (7), it is straightforward to compute the prior and posterior predictive probability distributions of $\mathrm{P}_{\mathrm{SA}}$ for the $\mathrm{SA}$ respondents alone: $P_{S A}=\frac{1}{\mathrm{~N}} \sum_{\mathrm{r}=0}^{\mathrm{N}} r e^{-\lambda} \frac{\lambda^{r}}{\mathrm{r} !}$. For the prior predictive probability distribution (i.e., prior PPD), we treated $\alpha$ of the Gamma distribution as a uniformly distributed random number between 0.5 and 2.0 (i.e., the same range used in the MCMC), and then for each realization of the Gamma distribution generated a value for $\lambda$. For the posterior PPD we picked a value of $\lambda$ from the PDF shown in Fig. 6b. These two predictive PDFs are shown in Fig. 7: in the case of the prior PPD the mean value of $\mathrm{P}_{\mathrm{SA}}$ was 0.15 with a $95 \%$ credible interval $(\mathrm{CI})$ of $[0.00,0.50]$, while in the case of the posterior PPD the mean value was 0.23 with a $95 \%$ CI of [0.20, 0.27]. Further, we note that for the prior $\mathrm{PPDP}_{\mathrm{SA}}$ has its maximum near zero, and then monotonically decreases until the "uptick" at $\mathrm{P}_{\mathrm{SA}}=0.5$. This can be explained by noting that at small values of $\lambda$ the most likely value of $r$ (i.e., the number of double responses) will be near zero, whereas for large values of $\lambda$ all values of $r$ become likely yielding a maximum possible value of $\mathrm{P}_{\mathrm{SA}}=0.5$.

We repeated the MCMC analysis for restricted sub-samples of our population: Males, Females, European-Americans (EA), and Hispanics (HI). (We only focused on these two ethnic groups, since they corresponded to the dominant portion of our sample.) The results for $\theta$ and $\lambda$ are displayed in Table 1, and illustrated in Fig. 8 along with $95 \%$ CIs. Superficially, we see no statistically significant differences in $\theta$ and $\lambda$ values for gender or ethnicity. Consequently, our data indicate that SA in general should not be considered a phenomenon restricted to one gender more than another, or necessarily manifesting itself in one ethnic group more than another: SA appears to be a phenomenon that (in general) transcends gender and ethnic differences.

This is not to suggest that SA for other questionnaires examining other controversial topics would not show gender and/or ethnic differences, and in this regard we can probe our own gender and ethnic differences a bit more deeply. Specifically, with the MCMC results, we can form probability density functions for $\Delta \lambda_{\text {gender }}$ and $\Delta \theta_{\text {gender }}$ (e.g., $\Delta \lambda_{\text {gender }}=$ $\lambda_{\text {Males }}-\lambda_{\text {Females }}$ ), with similar differences based on ethnicity 


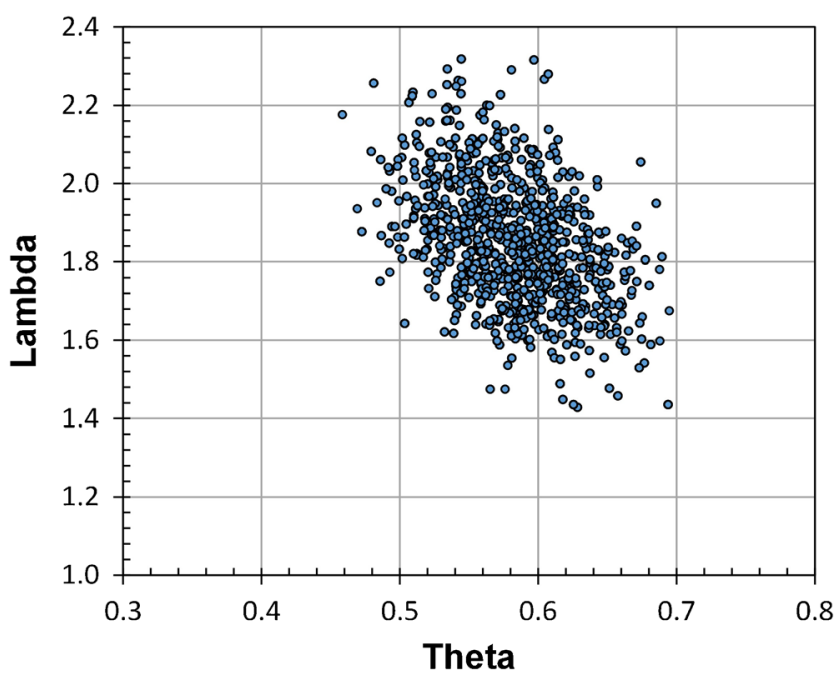

Fig. 5 Scattergram of $\lambda$ vs. $\theta$. The figure shows $\lambda$ vs. $\theta$ for $\alpha=1$ in the Gamma distribution. For visual clarity, only 20,000 data points are plotted
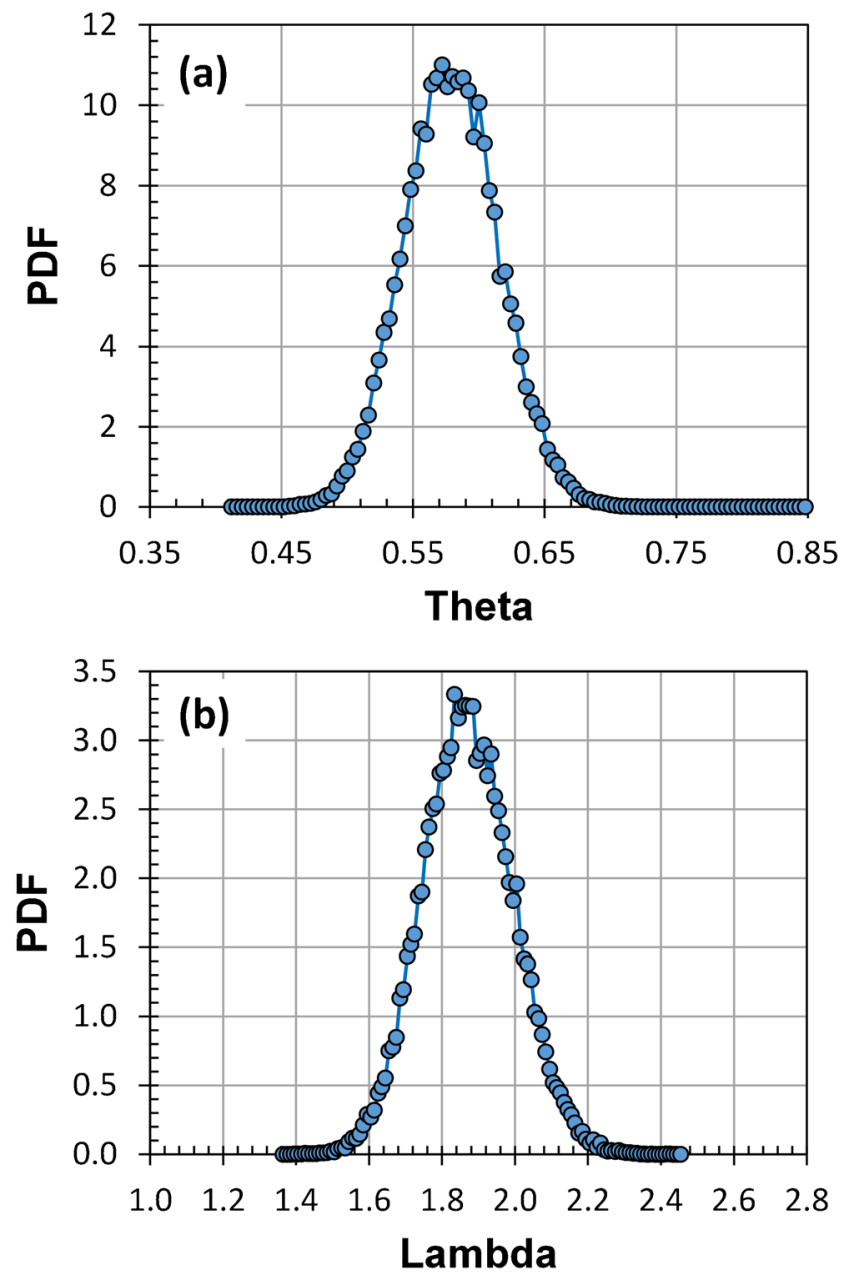

Fig. 6 Probability density functions (PDFs) from the Markov Chain Monte Carlo (MCMC) analysis: (a) PDF of $\theta$, and (b) PDF of $\lambda$. Both PDFs are very well described by normal distributions: for $\theta \mathrm{M}=0.58$ with $\mathrm{SD}=0.035$, and for $\lambda \mathrm{M}=1.87$ with $\mathrm{SD}=0.134$

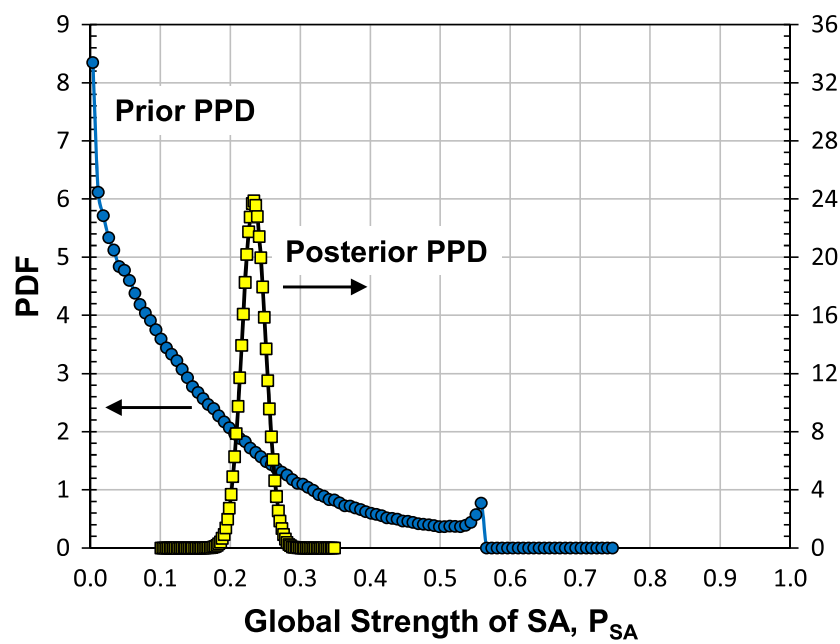

Fig. 7 Prior and posterior predictive probability distributions (PPDs) for simultaneously ambivalent (SA) respondents alone

(Kruschke, 2013). These PDFs are shown in Figs. 9 and 10, where it is clear that in all cases the $95 \%$ CI contains zero. That said, it is interesting to note that zero is just at the edge of the $95 \% \mathrm{CI}$ for $\Delta \lambda_{\text {gender }}$ (with females showing greater levels of SA than males), suggesting that gender differences in SA for affirmative action might be a fruitful area for further investigation.

\section{Simultaneous ambivalence versus vacillating ambivalence}

In addition to computing $\mathrm{S}_{\text {endorse}}$, the density matrix can also be employed to compute V-measures of vacillating ambivalence. Specifically, the diagonal elements of $\rho(\mathrm{k})$ can used to determine the number of times each subject disagreed and agreed with affirmative action: $\mathrm{N}_{\text {disagree }}$ and $\mathrm{N}_{\text {agree. }}$ In effect, the diagonal components can be used to count participants' favor/disfavor valence evaluations - after properly taking account of the SA participants' double responses. ${ }^{1}$ Taking the larger of $\mathrm{N}_{\text {disagree }}$ or $\mathrm{N}_{\text {agree }}$ as the participant's dominantattitude response number, $\mathrm{D}$, and the other as their conflicting-attitude response number, $\mathrm{C}$, we employed the

\footnotetext{
${ }^{1}$ Since the questionnaire had $\mathrm{N}=8$ items, the total number of items marked in disagreement is $N_{\text {disagree }}=N\left(\rho_{11}+\rho_{22}\right)$. Similarly, the total number of items marked in agreement is $\mathrm{N}_{\text {agree }}=\mathrm{N}\left(\rho_{44}+\rho_{55}\right)$. However, to compute VA we need to reduce these numbers by taking account of any double responses the subject may have made, since we do not want to mix SA into VA. This is relatively straightforward, since each double response is indicated in $\rho(\mathrm{k})$ by the off-diagonal density matrix elements. Specifically, for each double response we simply subtract one count from the total, which is accomplished by subtracting the appropriate off-diagonal density matrix elements from the diagonal elements:
}

$$
\begin{gathered}
N_{\text {disagree }} \rightarrow \mathrm{N}\left(\rho_{11}+\rho_{22}-\sum_{k=3}^{5}\left(\rho_{1 k}+\rho_{2 k}\right)\right) \\
N_{\text {agree }} \rightarrow \mathrm{N}\left(\rho_{44}+\rho_{55}-\sum_{k=1}^{3}\left(\rho_{4 k}+\rho_{5 k}\right)\right) .
\end{gathered}
$$


Table 1 Results of $\theta$ and $\lambda$ from the Markov Chain Monte Carlo (MCMC) analysis

\begin{tabular}{lllll}
\hline Category & Mean & Lower 95\% CI & Upper 95\% CI & ESS \\
\hline Lambda & & & & \\
Total & 1.87 & 1.63 & 2.12 & 26,300 \\
Female & 1.78 & 1.56 & 2.07 & 31,965 \\
Male & 2.08 & 1.64 & 2.57 & 62,482 \\
Euro-Am & 2.19 & 1.77 & 2.63 & 52,250 \\
Hispanic & 1.70 & 1.43 & 2.09 & 35,599 \\
Theta & & & & \\
Total & 0.58 & 0.51 & 0.65 & 26,722 \\
Female & 0.63 & 0.54 & 0.69 & 37,943 \\
Male & 0.49 & 0.38 & 0.61 & 61,617 \\
Euro-Am & 0.59 & 0.48 & 0.68 & 55,993 \\
Hispanic & 0.57 & 0.46 & 0.67 & 38,159 \\
\hline
\end{tabular}

CI credible interval, Euro-Am European American

Gradual Threshold Model (GTM) of Priester and Petty (1996) to compute a GTM-Score for each subject:

GTM-Score $=5(\mathrm{C}+1)^{0.4}-(\mathrm{D}+1)^{1 /(C+1)}$

Very briefly, this empirically motivated model for a VA score includes the notions that: (1) vacillating ambivalence increases in a decelerating manner with the number of conflicting valence assessments of an attitude object; (2) VA decreases as the number of dominant valence assessments of an attitude object increases; and (3) the influence of dominant assessments on VA is not a constant, but decreases with conflicting valence assessments. For an 8-item questionnaire, the GTM-scores for maximum and minimum VA, respectively, are +8.14 and -4.00 . Since the specific numbering of the

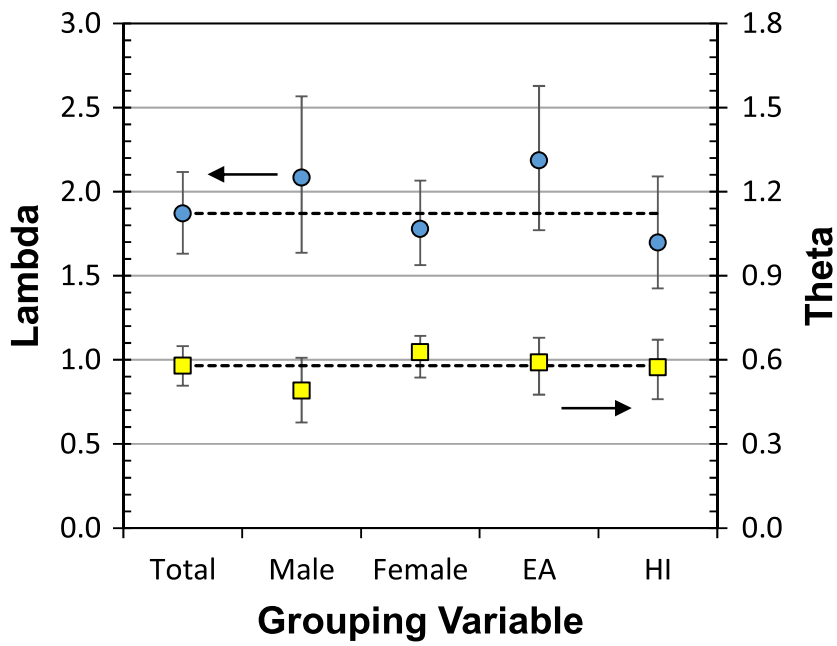

Fig. 8 Summary of results for $\theta$ and $\lambda$ from the various Markov Chain Monte Carlo (MCMC) analyses. Symbols correspond to the average value, while error bars correspond to the $95 \%$ credible interval (CI); the dashed lines correspond to the average values from the total-population MCMC
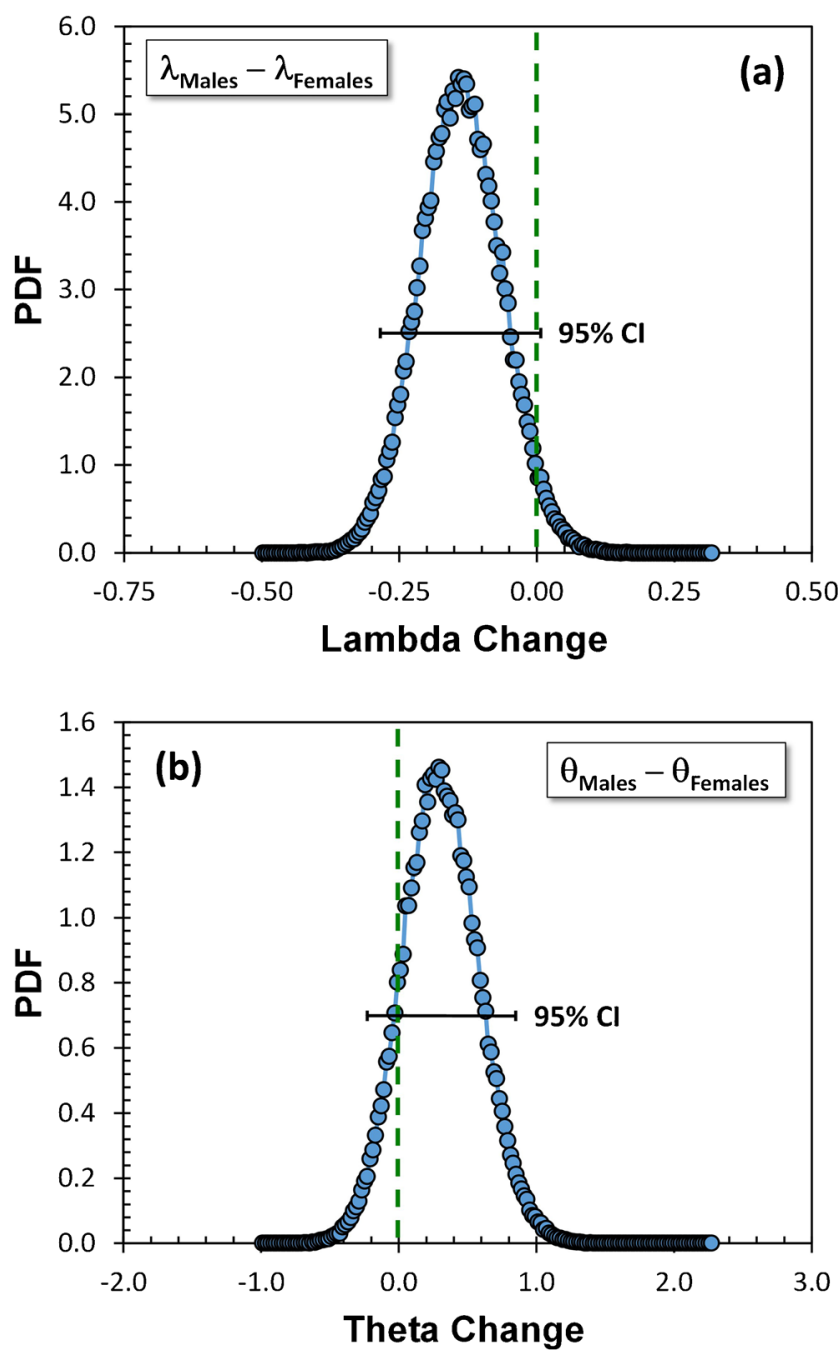

Fig. 9 Probability density functions (PDFs) from the Markov Chain Monte Carlo (MCMC) analysis for gender. (a) Corresponds to $\Delta \lambda_{\text {gender }}$ and (b) corresponds to $\Delta \theta_{\text {gender }}$ Notice that zero is just at the edge of the $95 \%$ credible interval $(\mathrm{CI})$ for $\Delta \lambda_{\text {gender }}$

GTM scale has no psychological or sociological meaning, we rescaled and normalized the GTM-scores for conceptual ease, labeling these rescaled GTM-scores as $\mathrm{S}_{\mathrm{VA}}$ : for no vacillating ambivalence $S_{\mathrm{VA}}=0.0$, and for maximum vacillating ambivalence $\mathrm{S}_{\mathrm{VA}}=1.0 .^{2}$

If $\mathrm{SA}$ and VA are distinct ambivalence constructs, then one would anticipate moderate to little correlation between $\mathrm{S}_{\mathrm{VA}}$ values and $\mathrm{P}_{\mathrm{SA}}$ strengths. To examine that correlation, we should first recognize that research has repeatedly demonstrated ethnic differences in attitudes towards affirmative action

\footnotetext{
${ }^{2}$ Given the discussion of Note $\# 1, \mathrm{~N}_{\text {disagree }}$ and $\mathrm{N}_{\text {agree }}$ will not necessarily sum to 8 . Thus, to create a consistently rescaled GTM-score, we set $M=D+C$. Then, the minimum GTM-score, $\mathrm{S}_{\min }$, will equal $4-\mathrm{M}$, and the maximum GTM-Score, $\mathrm{S}_{\max }$, will equal $5(\mathrm{M} / 2+1)^{0.4}-(\mathrm{M} / 2+1)^{2 /(\mathrm{M}+2)}$. We then have

$\mathrm{S}_{\mathrm{VA}}=\left(\mathrm{GTM}-\mathrm{Score}-\mathrm{S}_{\min }\right) /\left(\mathrm{S}_{\max }-\mathrm{S}_{\min }\right)$,

with $\mathrm{S}_{\min }$ and $\mathrm{S}_{\max }$ computed separately for each subject.
} 

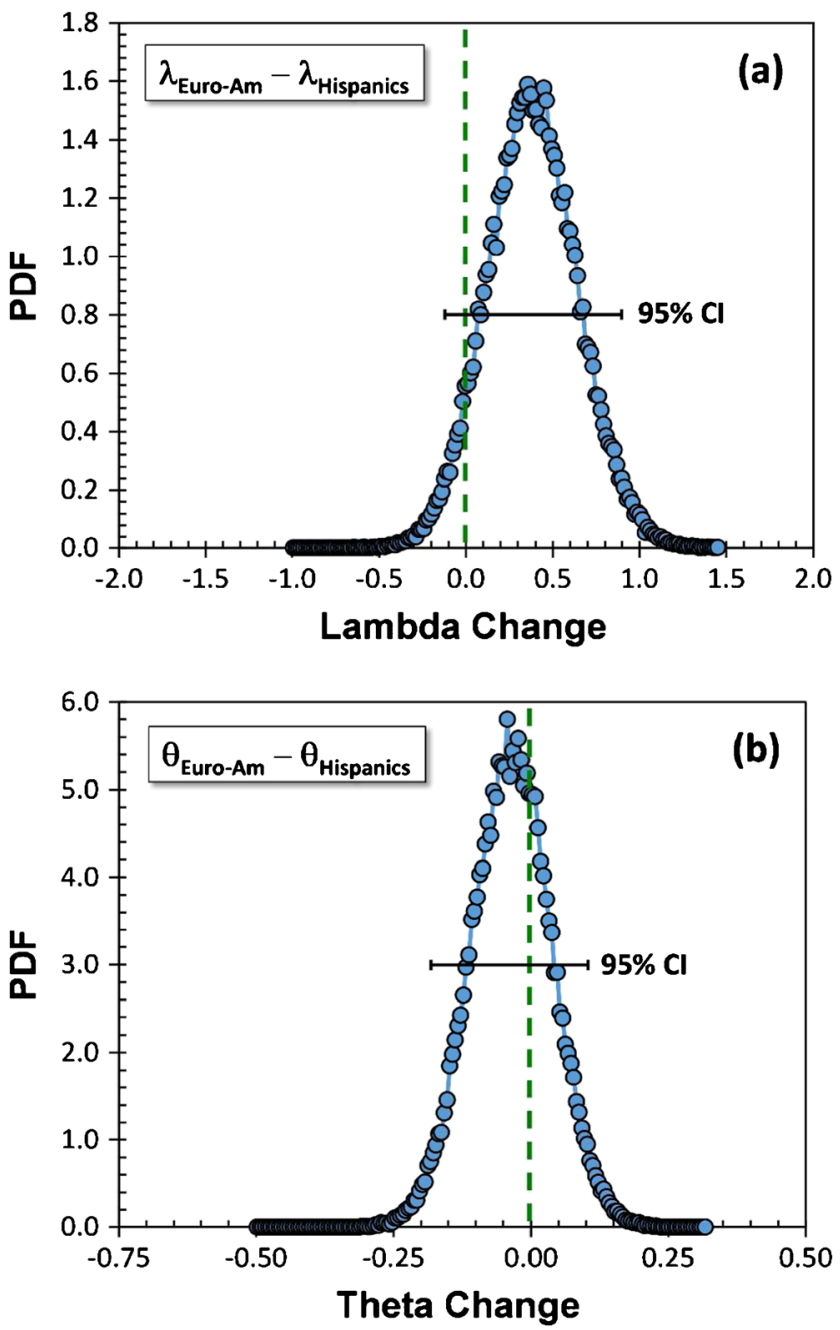

Fig. 10 Probability density functions (PDFs) from the Markov Chain Monte Carlo (MCMC) analysis for ethnicity. (a) Corresponds to $\Delta \lambda_{\text {ethnicity }}$ and (b) corresponds to $\Delta \theta_{\text {ethnicity }}$

(Kravitz \& Klineberg, 2000; Park, 2009; Zamani-Gallaher 2007), with the ethnic differences influenced by a number of factors including socio-economic factors (Sax \& Arredondo, 1999) and the strength of ethnic identity (Elizondo \& Crosby, 2004). Therefore, to avoid adding variance to a potential $\mathrm{S}_{\mathrm{VA}} /$ $\mathrm{P}_{\mathrm{SA}}$ correlation, we examined Euro-American and Hispanic participants separately. Figure 11 illustrates the $\mathrm{S}_{\mathrm{VA}} / \mathrm{P}_{\mathrm{SA}}$ correlation only employing SA participants: for the EA participants we found $\mathrm{r}(55)=-0.22$ with a $95 \% \mathrm{CI}$ of $[-0.48,0.07]$, and for the HI participants $\mathrm{r}(59)=-0.16$ with a $95 \% \mathrm{CI}$ of $[-0.41,0.10]$. The overlap of zero for the $95 \%$ CIs (for both values of $r$ ) is consistent with the contention that VA and SA are distinct ambivalence constructs.

\section{Summary}

In this work, we discussed the density matrix's utility as a new statistical tool for the study of ambivalence, and examined its capabilities in an exploratory methodological study. Taking double responding to questionnaire items as the criterion for simultaneous ambivalence, SA, we found that a large fraction of a sample population will exhibit SA when their attitudes are examined regarding a controversial topic like affirmative action, and in general the large fraction does not appear to be restricted by gender or ethnicity. Using the density matrix, we were also able to model the probability distribution of simultaneous ambivalence strengths $\left(\mathrm{P}_{\mathrm{SA}}\right)$ using a mixture model, with $\mathrm{p}\left[\mathrm{P}_{\mathrm{SA}}\right]$ for the SA subjects well described by a Poisson distribution. Additionally, we found that SA and VA (vacillating ambivalence) appear to be two distinct ambivalence constructs, which to date have not been adequately distinguished in the literature.

Of course, the present work has also raised a number of new questions regarding ambivalence. For example, from a basic social sciences perspective it will be important to uncover the social/psychological factors (if any) that distinguish SA and non-SA individuals. These factors might include the need for cognition, and might also contain a cognitive development component. For example, do instances and levels of SA (and VA) change as one transitions from developmentally earlier forms of reasoning to more mature forms of reasoning, and if so, do SA and VA change in a correlated fashion with increases in VA predicting increases in SA? Moreover, we think it will be important to probe for the antecedents of SA and VA, and examine the extent to which these antecedents are the same (or different).

Additionally, future research will need to consider environmental factors that might distinguish SA and non-SA respondents. Specifically, it may be the case that SA and non-SA respondents are not intrinsically different, but rather that any individual can respond in an SA, or non-SA fashion depending on external influences (e.g., questionnaire length, personal relevance of the questionnaire items to the respondent, level of fatigue). In this same vein, future research should examine the role of questionnaire item wording and its ability to foster (or inhibit) SA, along with the role of questionnaire item organization (i.e., items presented early in a survey might foster SA responses to questionnaire items that come later in the survey).

Regardless of the outcomes of future research, it seems clear that the density matrix has much to offer researchers interested in quantifying ambivalence. In particular, we believe that the density matrix will help clarify the distinction between SA and VA, and in that way help illuminate the cognitive processes underlying attitude formation and attitude change. We also believe, however, that the density matrix could play a more utilitarian role. Specifically, by better quantifying ambivalence among groups (e.g., between EuroAmerican and African-Americans regarding affirmative action, or between those presenting themselves as pro-choice or pro-life in the abortion debates), we believe that greater understanding might be achieved in the social arena, thereby 


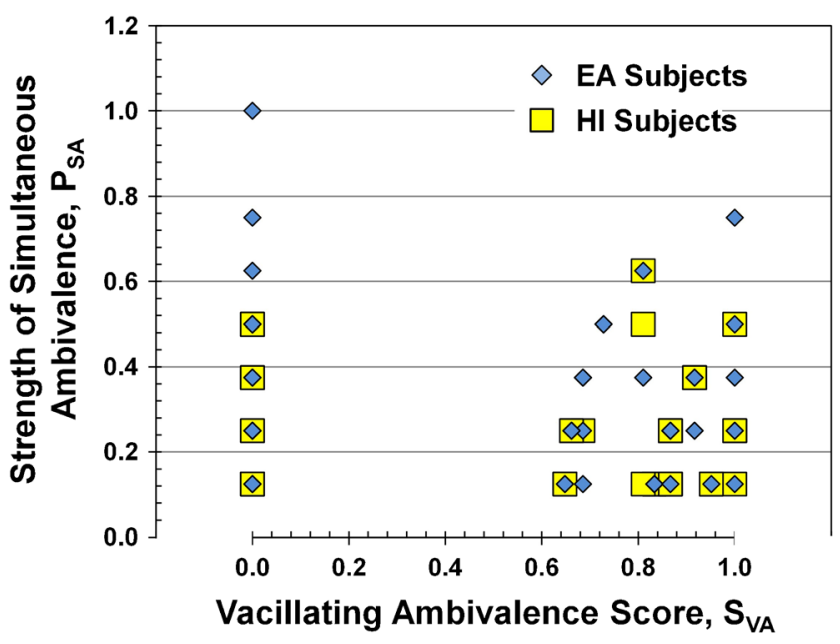

Fig. $11 \mathrm{~S}_{\mathrm{VA}} / \mathrm{P}_{\mathrm{SA}}$ Correlation. Considering only the simultaneously ambivalent (SA) participants, this figure shows a scattergram of the participants' strengths of simultaneous ambivalence, $\mathrm{P}_{\mathrm{SA}}$, versus their vacillating ambivalence score, $\mathrm{S}_{\mathrm{VA}}$. There is clearly little if any correlation

leading to the discovery of common ground among groups regarding many apparently divisive issues.

Acknowledgment The authors thank Prof. Michael Lee for his extensive comments during the review process, which materially improved the quality of this work.

\section{Appendix 1: Affirmative action essay}

Affirmative action is a combative issue, with fair-minded people on both sides of the debate holding strong and passionate positions. At its heart, the debate can be viewed as centering on the issue of how America is to move towards a more ideal society: a society where advancement and success are based on an individual's talent and hard work and not the color of their skin, or the amount of money in their pockets, or their gender. In other words, how do we move America to a more ideal "meritocracy"?

On one side of the debate are those individuals who recognize that minorities and women have faced (and still face) difficult challenges. For nearly three-hundred years, AfricanAmericans were not recognized as members of society; they were property. And though this was legally altered 150 years ago, after the American Civil War, the change in society's collective mind has been much slower. We are within a generation of a time when African-Americans could not go to publically funded state universities, when they could not drink water from the same fountain as Whites, and when legallysanctioned rules effectively denied these citizens (citizens in name if not in fact) the right to vote. Additionally, we are within a generation of a time when Latino farm workers were treated no better than slaves, and when the future of their children was radically more limited than that of their White neighbors. Finally, though it has been nearly 100 years since women won the right to vote, women are still routinely paid less than men for the same work.

Individuals on this side of the debate argue that if America is to become a true meritocracy, then we must recognize the unique obstacles faced by minorities and women, and we must "level the playing field": if women and minorities are at disadvantage for success in society, then we must compensate by giving them the advantage of special consideration.

On the other side of the debate are those individuals who recognize that justice must be blind; not simply justice before the law, but justice with regard to opportunity. If we truly want people to succeed based on their merit, then colleges should not place unfair obstacles in the path of minorities applying for admission, and they should not create unfair rules placing Whites at disadvantage in their applications. If we truly want the best and brightest leading our businesses, then we should not base promotion and pay on gender: we should not favor men over women and we should not favor women over men. Moreover, providing special consideration for minorities and women is degrading, since it suggests that minorities and women cannot succeed on a truly level playing field. It perpetuates the myth that minorities and women can only succeed if White males "bend the rules" in minorities' and women's favor.

Individuals on this side of the debate argue that if America is to become a true meritocracy, then we must recognize that a level playing field means exactly that: all individuals in society must be treated equally. If women and minorities are to have real advantage for success in society, then we must recognize that this can't be achieved by providing other (perhaps more fortunate) members of society with disadvantage. Women and men, Whites and minorities, must fall or rise on their own, much like an athlete falls or rises to greatness based on his or her own ability.

\section{Appendix 2: Instructions and questionnaire items}

A. Definition - The Merriam-Webster dictionary defines affirmative action as "an active effort to improve the employment or educational opportunities of members of minority groups and women."

B. Please carefully read the following comments on affirmative action. [The affirmative action essay, Appendix 1, was given to the participants here.]

C. Please carefully read each of the following statements, and indicate your level of agreement or disagreement by circling a number on the scale provided. [A linear scale was provided below each item with the following equally spaced marks and words on the scale: $1=$ Strongly Disagree, 2 = Disagree, 3 = I Truly Have No Opinion, 4 = Agree, $5=$ Strongly Agree.] If you believe that a single 
response does not accurately capture your feelings regarding the statement, YOU CAN CIRCLE TWO NUMBERS. For example, you may feel that you agree AND you disagree with a certain statement. In such a case, feel free to circle two numbers reflecting your levels of agree and disagree.

1. Affirmative action is good for society.

2. Companies should provide special advantages for women.

3. Companies must have the exact same hiring criteria for all racial/ethnic-group applicants.

4. Affirmative action is bad for society.

5. Since White children often wind up going to better schools, admissions standards at the best colleges and universities should be adjusted for minorities.

6. In business, providing special advantages to one gender (male or female) is wrong.

7. College admission standards should be applied equally, regardless of racial or ethnic-group.

8. Companies must compensate for the unique difficulties different ethnic groups have faced in their history and which they still may face.

\section{References}

Armitage, C. J., \& Conner, M. (2000). Attitudinal ambivalence: A test of three key hypotheses. Personality and Social Psychology Bulletin, 26, 1421-1432.

Baek, Y. M. (2010). An integrative model of ambivalence. The Social Science Journal, 47, 609-629.

Basinger, S. J., \& Lavine, H. (2005). Ambivalence, information, and electoral choice. American Political Science Review, 99, 169-184.

Blum, K. (1981). Density matrix theory and applications. New York: Plenum.

Böhning, D., \& Seidel, W. (2003). Editorial: recent developments in mixture models. Computational Statistics \& Data Analysis, 41, 349-357.

Busemeyer, J. R., Wang, Z., Khrennikov, A., \& Basieva, I. (2014). Applying quantum principles to psychology. Physica Scripta, T163, 014007.

Busemeyer, J. R., \& Wang, Z. (2015). What is quantum cognition, and how is it applied to psychology. Current Directions in Psychological Science, 24, 163-169.

Bushong, S. C. (1988). Magnetic resonance imaging - Physical and biological principles. St Louis: The C. V. Mosby Co.

Camparo, J. C. (2013). A geometrical approach to the ordinal data of Likert scaling and attitude measurements: The density matrix in psychology. Journal of Mathematical Psychology, 57, 29-42.

Camparo, J., \& Camparo, L. B. (2013). The analysis of Likert scales using state multipoles: An application of quantum methods to behavioral sciences data. Journal of Educational and Behavioral Statistics, 38, 81-101.

Conner, M., Sparks, P., Povey, R., James, R., Shepherd, R., \& Armitage, J. C. (2002). Moderator effects of attitudinal ambivalence on attitude-behavior relationships. European Journal of Social Psychology, 32, 705-718.
Crano, W. D., Cooper, J., \& Forgas, J. P. (2010). Attitudes and attitude change. In J. P. Forgas, J. Cooper, \& W. D. Crano (Eds.), The psychology of attitudes and attitude change (pp. 3-17). New York: Taylor \& Francis Group.

Davenport, W. B. (1970). Probability and random processes: An introduction for applied scientists and engineers (p. Ch. 13). New York: McGraw-Hill.

Dirac, P. A. M. (1947). The principles of quantum mechanics. London: Oxford Press.

Eagly, A. H., \& Chaiken, S. (1993). The psychology of attitudes. Orlando: Harcourt Brace Jovanovich

Elizondo, E., \& Crosby, F. (2004). Attitudes toward affirmative action as a function of the strength of ethnic identity among Latino college students. Journal of Applied Social Psychology, 34(9), 1773-1796.

Fano, U. (1957). Description of states in quantum mechanics by density matrix and operator techniques. Reviews of Modern Physics, 29(1), 74-93.

Himmelfarb, S. (1993). The measurement of attitudes. In A. H. Eagly \& S. Chaiken (Eds.), The psychology of attitudes. Orlando: Harcourt Brace Jovanovich.

Jonas, K., \& Ziegler, R. (2007). Attitudinal ambivalence. In M. Hewstone, H. A. W. Schut, J. B. F. DeWit, K. Van den Bos, \& M. S. Stroebe (Eds.), The scope of social psychology: Theory and applications (pp. 29-42). New York: Psychology Press.

Kachadourian, L. K., Fincham, F., \& Davila, J. (2005). Attitudinal ambivalence, rumination, and forgiveness of partner transgressions in marriage. Personality and Social Psychology Bulletin, 31, 334-342.

Kaplan, K. J. (1972). On the ambivalence-indifference problem in attitude theory and measurement: A suggested modification of the semantic differential technique. Psychological Bulletin, 77, 361-372.

Kravitz, D. A., \& Klineberg, S. L. (2000). Reactions to two versions of affirmative action among whites, blacks, and Hispanics. Journal of Applied Psychology, 85(4), 597-611.

Kruschke, J. K. (2013). Bayesian estimation supersedes the t test. Journal of Experimental Psychology: General, 142(2), 573-603.

Locke, K. D., \& Braun, C. C. (2009). Ambivalence versus valence: Analyzing the effects of opposing attitudes. Social Cognition, 27, 89-104.

Louisell, W. H. (1973). Quantum statistical properties of radiation (p. 1). New York: John Wiley \& Sons, Ch.

Marsaglia, G., \& Tsang, W. W. (2000). A simple method for generating gamma variables. ACM Transactions on Mathematical Software, 26, 363-372.

McGraw, K. M., Hasecke, E., \& Conger, K. (2003). Ambivalence, uncertainty, and processes of candidate evaluation. Political Psychology, 24, 421-448.

Mendenhall, W., Scheaffer, R. L., \& Wackerly, D. D. (1986). Mathematical statistics with applications (p. 3). Boston: Prindle, Weber \& Schmidt, Ch.

Newby-Clark, I. R., McGregor, I., \& Zanna, M. P. (2002). Thinking and caring about cognitive inconsistency: When and for whom does attitudinal ambivalence feel uncomfortable? Journal of Personality and Social Psychology, 82, 157-166.

Park, J. J. (2009). Taking race into account: Charting student attitudes towards affirmative action. Research in Higher Education, 50, 670-690.

Priester, J. R., \& Petty, R. E. (1996). The gradual threshold model of ambivalence: Relating the positive and negative bases of attitudes to subjective ambivalence. Journal of Personality and Social Psychology, 71, 431-449.

Russell, C. A., Russell, D. W., \& Klein, J. (2011). Ambivalence toward a country and consumers' willingness to buy emblematic brands: The differential predictive validity of objective and subjective ambivalence measures on behavior. Marketing Letters, 22, 357-371.

Sax, L. J., \& Arredondo, M. (1999). Student attitudes toward affirmative action in college admissions. Research in Higher Education, 40(4), 439-459.

Song, H., \& Ewoldsen, D. R. (2015). Metacognitive model of ambivalence: The role of multiple beliefs and metacognitions in creating attitude ambivalence. Communication Theory, 25, 23-45. 
Spector, P. E. (1992). Summated rating scale construction: An introduction. Newbury Park: Sage Publications.

Thompson, M. M., \& Zanna, M. P. (1995). The conflicted individual: Personality-based and domain-specific antecedents of ambivalent social attitudes. Journal of Personality, 63, 259-288.

Thompson, M. M., Zanna, M. P., \& Griffin, D. W. (1995). Let's not be indifferent about (attitudinal) ambivalence. In J. E. Petty \& J. A. Krosnick (Eds.), Attitude strength: Antecedents and consequences (pp. 361-386). Mahwah: Lawrence Erlbaum Associates.

Tourangeau, R., \& Rasinski, K. A. (1988). Cognitive processes underlying context effects in attitude measurement. Psychological Bulletin, 103, 299-314.
Zaller, J., \& Feldman, S. (1992). A simple theory of the survey response: Answering questions versus revealing preferences. American Journal of Political Science, 36, 579-616.

Zamani-Gallaher, E. M. (2007). The confluence of race, gender, and class among community college students: Assessing attitudes towards affirmative action in college admissions. Equity \& Excellence in Education, 40, 241-251.

Zemborain, M. R., \& Johar, G. V. (2007). Attitudinal ambivalence and openness to persuasion: A framework for interpersonal influence. Journal of Consumer Research, 33, 506-514. 